Objectives: To understand if changes in patient reported outcomes (PROs) differ among patients with $1^{\circ}$ or $2^{\circ} \mathrm{TNFi}$ failure.

Methods: In TARGET (NCT10709758), patients with intolerance or an inadequate response to TNFi were randomised to placebo or sarilumab $150 \mathrm{mg}$ or $200 \mathrm{mg}$ plus csDMARD. For patients with an inadequate response to TNFi (92\% of the sample), $1^{\circ}$ or $2^{\circ}$ failure was investigator-determined at enrollment. The following PROs were assessed at Week 0 (treatment initiation) and Week 24: HAQDI, patient global assessment of disease visual analogue scale (VAS), pain VAS, SF-36, morning stiffness VAS, EQ-5D, and Rheumatoid Arthritis Impact of Disease (RAID) scale. All scales produce global (total) scores, except the SF-36 which has eight domains and two summary scores (physical and mental component scores [PCS and MCS]) and the EQ-5D which has a single index utility score and a global health VAS. The PRO change from baseline was analysed through mixed model repeated measures with treatment, region, number of prior TNFis, baseline of the PRO analysed, visit, treatment-by-visit interaction, $1^{\circ}$ and $2^{\circ}$ subgroup, treatment-by-subgroup interaction, and treatment-by-visit-by-subgroup interaction. Post-hoc analysis of the sarilumab $200 \mathrm{mg}$ data are reported here as this is the recommended dose of sarilumab.

Results: In this post-hoc analysis, 174 of 181 patients in the placebo group and 167 of 184 in the sarilumab $200 \mathrm{mg}$ group were classified as $\mathrm{TNFi} 1^{\circ}$ or $2^{\circ}$ failures (the remaining patients were classed as intolerant or other and not included in this analysis); 75 and 64 were $1^{\circ}$ and 99 and 103 were $2^{\circ}$ treatment failures in the placebo and the sarilumab $200 \mathrm{mg}$ groups, respectively. At Week 24, changes in all $\mathrm{PROs}$ were numerically similar in the $1^{\circ}$ or $2^{\circ} \mathrm{TNFi}$ failures for both the sarilumab $200 \mathrm{mg}$ and placebo groups (table 1). Furthermore, treatment-by-subgroup interaction testing did not show a statistically significant interaction of TNFi failure status and PRO outcome (all interaction $P$-values $>0.05$ ). Treatment emergent adverse events occurred in $65.6 \%$ of sarilumab $200 \mathrm{mg}$ patients in the $1^{\circ}$ failure group and $63.1 \%$ in the $2^{\circ}$ failure group and were consistent with safety data reported previously.

Abstract FRI0144 - Table 1. Least square mean (SE) change from baseline to Week 24 in patient-reported outcomes with sarilumab $200 \mathrm{mg}$ and placebo following primary and secondary TNFi failure

\begin{tabular}{|c|c|c|c|c|c|}
\hline PRO & Placbobo & Sartitumob $200 \mathrm{mog}$ & Plocobo & $\begin{array}{l}\text { urro } \\
\text { Sarliumab } 200 \mathrm{mg}\end{array}$ & ion Pvalue" \\
\hline Pationt giobal assossmant & $\frac{(n=75)}{-2256(3.35)}$ & 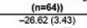 & 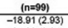 & 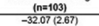 & \\
\hline $\begin{array}{l}\text { Pain vaS } \\
\text { HAD-OD }\end{array}$ & $\begin{array}{l}-21.25(3.568) \\
-0.0300098\end{array}$ & $\begin{array}{l}-31.81(3.57) \\
-0.520 .081)\end{array}$ & 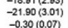 & 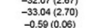 & $\begin{array}{l}0.8390 \\
0.1672 \\
0.1972\end{array}$ \\
\hline 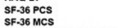 & 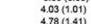 & $\begin{array}{l}8.78(1.01) \\
558(14)\end{array}$ & $\begin{array}{l}4.61(0.99) \\
484(121)\end{array}$ & 7.9510 .090 & $\begin{array}{l}0.7237 \\
0.7237 \\
\end{array}$ \\
\hline 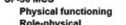 & $\begin{array}{l}4.78(1.44) \\
5: 98(2.26)\end{array}$ & 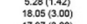 & $\begin{array}{l}4.84(1.27) \\
10.40(279)\end{array}$ & $\begin{array}{l}6.81(1,10) \\
14 \pi(2.23)\end{array}$ & $\begin{array}{l}0.0326 \\
0.2095 \\
0.059\end{array}$ \\
\hline 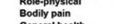 & $\begin{array}{l}9.10(3.303) \\
14.51(299)\end{array}$ & $\begin{array}{l}17.93(3.200) \\
25.353(2.93)\end{array}$ & $\begin{array}{l}11.175(2.76) \\
18.32 .63)\end{array}$ & $\begin{array}{l}20.01(2429) \\
20.02(20)\end{array}$ & $\begin{array}{l}0.0974 \\
0.8947\end{array}$ \\
\hline $\begin{array}{l}\text { Generart hestith } \\
\text { Vitatily }\end{array}$ & $\begin{array}{l}1.10(2.28) \\
0.19(2.58)\end{array}$ & 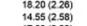 & $\begin{array}{l}7.000(21.17) \\
0.05(230)\end{array}$ & 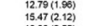 & $\begin{array}{l}0.8198 \\
0.9265\end{array}$ \\
\hline $\begin{array}{l}\text { Social turentioning } \\
\text { Role emotional }\end{array}$ & $\begin{array}{l}1293(323) \\
10.46(339) \\
1034\end{array}$ & 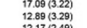 & 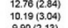 & $\begin{array}{l}1806(25.5) \\
15.55(2.22)\end{array}$ & $\begin{array}{l}0.8857 \\
0.0854\end{array}$ \\
\hline $\begin{array}{l}\text { Mentall nealth } \\
\text { FACIT-Aatigue }\end{array}$ & $\begin{array}{l}6.09(2.949) \\
7.19(1.38)\end{array}$ & 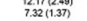 & $\begin{array}{l}9.90(2.13) \\
6.50(1.14)\end{array}$ & $\begin{array}{l}1.97(1,93) \\
10.35(1.04)\end{array}$ & $\begin{array}{l}0.5772 \\
0.1630\end{array}$ \\
\hline $\begin{array}{l}\text { Marming g vithoss VAS } \\
\text { EQ.SD VAS }\end{array}$ & $\begin{array}{l}-21.83(3.58) \\
1.72(3.32)\end{array}$ & 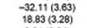 & $\begin{array}{l}-22227(1238) \\
12.51(2283)\end{array}$ & 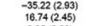 & $\begin{array}{l}0.817 \\
0.5919\end{array}$ \\
\hline 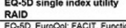 & $\begin{array}{l}0.018(0.0 .94) \\
-1.14(031)\end{array}$ & & & $\begin{array}{ll}0.3510 .039 \\
-281025\end{array}$ & \\
\hline
\end{tabular}

Conclusions: In TNFi inadequate response patients, following treatment with sarilumab $200 \mathrm{mg}+\mathrm{CsDMARD}$, changes in PRO outcomes were similar, regardless of whether they had experienced $1^{\circ}$ or $2^{\circ} \mathrm{TNFi}$ failure, suggesting that sarilumab is suitable for both $1^{\circ}$ and $2^{\circ} \mathrm{TNFi}$ failure patients.

Acknowledgements: The study was funded by Sanofi and Regeneron Pharmaceuticals, Inc.

Disclosure of Interest: V. Strand Consultant for: AbbVie, Amgen, AstraZeneca, Biogen, BMS, Celltrion, CORRONA, Crescendo, Genentech/Roche, GSK, Janssen, Eli Lilly, Novartis, Pfizer, Regeneron Pharmaceuticals Inc., Sandoz, Sanofi and UCB, S. Boklage Shareholder of: Regeneron Pharmaceuticals, Inc., Employee of: Regeneron Pharmaceuticals, Inc., E. Mangan Shareholder of: Regeneron Pharmaceuticals, Inc., Employee of: Regeneron Pharmaceuticals, Inc., M. Reaney Shareholder of: Sanofi, Employee of: Sanofi, M. Iglesias-Rodriguez Shareholder of: Sanofi, Employee of: Sanofi, T. Kimura Shareholder of: Regeneron Pharmaceuticals, Inc., Employee of: Regeneron Pharmaceuticals, Inc.

DOI: 10.1136/annrheumdis-2018-eular.3668

\section{FRI0145 A BAYESIAN NETWORK META-ANALYSIS ON EFFICACY OF BIOLOGICS AND SMALL MOLECULES IN EARLY RHEUMATOID ARTHRITIS}

V. Venerito, F. Cacciapaglia, G. Lapadula, F. lannone. Department of Emergency and Organ Transplantations, Rheumatology Unit, University of Bari "Aldo Moro", Bari, Italy

Background: The use of several biologic drugs as well as small molecules, in combination or not with methotrexate (MTX), is licensed for the treatment of Rheumatoid Arthritis (RA). Treating patients within the 'therapeutic window of opportunity' may reset the disease's long-term trajectory. Which agent would fit better the need of promptly achieving remission of patients affected with early RA is currently a matter of debate. Ideally head to head comparison are required to estimate which treatment is the most effective. Alternatively, indirect comparisons based on a common comparator may be useful. Previous indirect comparisons did not take into account all the biologics and small molecules approved for the treatment of RA, being also biassed, identifying early RA in patients with high variance of disease duration, ranging from to 6 months to 2 years.

Objectives: To provide an estimate through a Bayesian Network Meta-Analysis of which biologic or small molecule in association with MTX is more likely to determine a good clinical response in patients affected with early RA (i.e. mean disease duration $<1$ year).

Methods: A literature search was performed in accordance with the Preferred Reporting Items for Systematic Reviews and Meta-analyses (PRISMA) statement to identify results of Randomised Controlled Trials (RCTs) of biologic agents and small molecules at licensed doses to treat patients affected by early RA. MEDLINE, EMBASE, Cochrane Library, and Clinicaltrials.gov were searched for all published RCTs ranging from 1990 to September 2017. Patients had to fulfil the ACR 1988 revised criteria and/or the 2010 ACR/EULAR criteria for classified RA We included all completed RCTs of biologics or small molecules in combination with MTX, compared with MTX plus placebo or in combination with other biologics or small molecules, in patients whose RA had mean duration of less than 1 year. American College of Rheumatology (ACR) 50\% response and ACR $70 \%$ response had to be evaluated after one year of continuous treatment both in examined drug branch and in placebo branch. WinBUGS 1.4 software (MRC Biostatistics Unit, Cambridge, UK) was used to perform the analyses, using a a fixedeffect model.

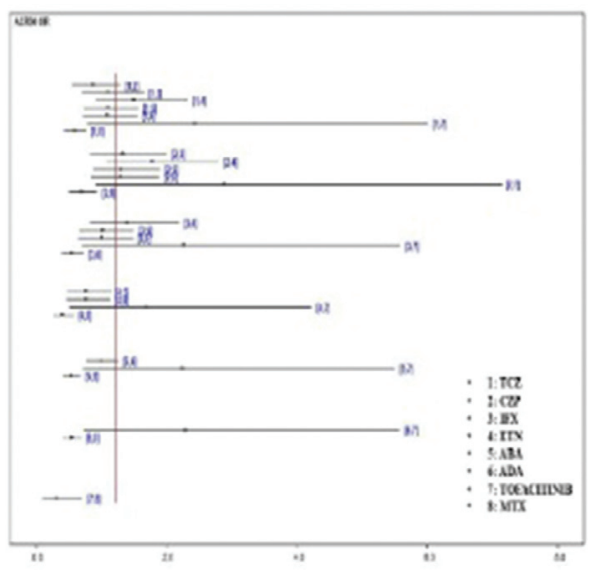

Results: Thirteen studies were included in the analysis. All the biologics as well as Tofacitinib proved to be more effective than MTX plus placebo in inducing an ACR50 response. In this regard, Tofacitib was the most effective overall (probability of being the best treatment: $75.04 \%)$ followed by Etanercept $(21.52 \%)$. The agent with the highest probability of inducing ACR70 response was Etanercep $(52.00 \%)$ followed by Abatacept $(20.22 \%)$. All compared biologics in combination with MTX were superior to MTX alone in inducing ACR70 response.

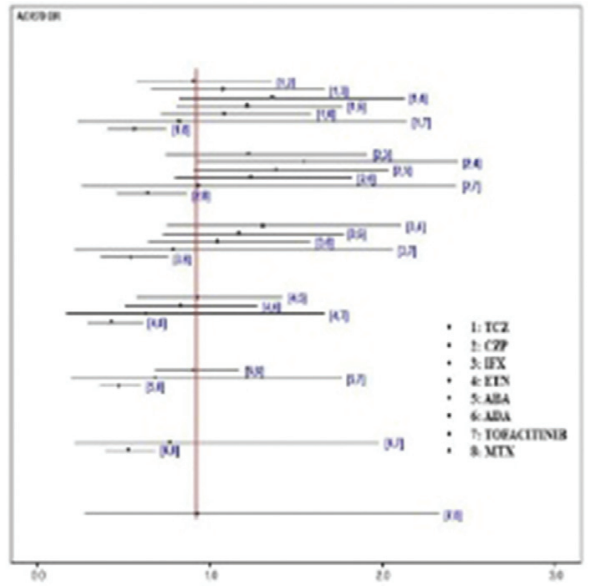

Conclusions: After one year of continuous treatment, Tofacitinib and Etanercept are the agents with the highest probability of inducing ACR50 response in patients 
affected by early RA, while Etanercept and Abatacept are the biologics with the highest probability of inducing ACR70.

\section{REFERENCE:}

[1] Migliore A, et al. The Challenge of Treating Early-Stage Rheumatoid Arthritis: The Contribution of Mixed Treatment Comparison to Choosing Appropriate Biologic Agents. BioDrugs 2016;30(2):105-115.

Disclosure of Interest: None declared

DOI: 10.1136/annrheumdis-2018-eular.4759

\section{FRI0146 CORRELATION BETWEEN THE RHEUMATOID FACTOR POSITIVITY AND THE HIGHER DISCONTINUATION RATE OF BIOLOGICAL THERAPY IN RHEUMATOID ARTHRITIS: A FINE-GREY PROPORTIONAL HAZARD REGRESSION ANALYSIS}

Y. Ogawa ${ }^{1}$, N. Takahashi ${ }^{2}$, T. Kojima ${ }^{2}$, N. Ishiguro ${ }^{2}{ }^{1}$ Nakatsugawa Municipal General Hospital, Nakatsugawa; ${ }^{2}$ Nagoya University Graduate School of Medicine, Nagoya, Japan

Background: As quantifying the occurrence of outcome over time holds vital importance in clinical medicine, the presence of competing risks must be considered when assessing the impact of prognostic factors on the incidence of an outcome over time. A competing risk is defined as an event that precludes the occurrence of an event of interest. For example, event arising from adverse effect causes is a competing risk when evaluating the effect of risk factors on the incidence of discontinuation of biological therapy because of inadequate response. The presence of biassed estimates of the effect of covariates on the incidence in the presence of competing risks is attributed to the naïve use of the conventional Cox proportional hazards model that censors the competing event. Fine and Grey developed the subdistribution hazard model that facilitates modelling the effects of covariates on the cumulative incidence function in the presence of competing risks.

Objectives: The discontinuation of biological therapy in rheumatoid arthritis (RA) is attributed to several reasons, including inadequate response, adverse effect, remission, and changing hospital. In particular, inadequate response constitutes a principal and compelling reason. This study aims to investigate the correlation between covariates, including the rheumatoid factor (RF) positivity and the discontinuation of biological therapy due to inadequate response in bio-naïve patients with RA using the Fine-Grey proportional hazard regression for competing events.

Methods: In this study, we enrolled patients in the Tsurumai Biologic Communication Registry that comprises Nagoya University and 15 affiliated institutions in Japan. We assessed the correlation between individual characteristic components and patient outcomes using the Fine-Grey proportional hazard regression for competing events. Apparently, time-based models estimate the effects of various characteristics (e.g., RF positivity, sex, and age) on time to develop events of interest, including the discontinuation owing to inadequate response. The FineGrey proportional hazard regression considered competing events, implying that this model generated separate hazard ratios for each competing event. All analyses were conducted in EZR version 1.36.

Results: A higher crude discontinuation rate was observed due to inadequate response in RF-positive patients than that in RF-negative patients using the cumulative incidence function of competing events and Grey test (figure 1). After adjusting for the baseline characteristics, including age, sex, stage, disease at the baseline, methotrexate use, prednisolone use, and tumour necrosis factor inhibitor (TNFi) or non-TNFi (HR, 1.57; 95\% Cl: 1.01-2.43; $\mathrm{p}<0.05$; table 1 ), the difference was significant in the Fine-Grey proportional hazard regression analysis.

\begin{tabular}{lcccc}
\hline & Hazard ratio & Lower 95\% Cl & Upper 95\% Cl & p.value \\
\hline RF positivity & 1.57 & 1.01 & 2.43 & $<0.05$ \\
Sex & 0.91 & 0.61 & 1.36 & 0.67 \\
Age & 0.99 & 0.98 & 1.01 & 0.12 \\
Das28esr at baseline & 1.31 & 1.15 & 1.48 & $<0.05$ \\
non-TNFi & 0.53 & 0.31 & 0.91 & $<0.05$ \\
MTX use & 1.64 & 1.01 & 2.67 & $<0.05$ \\
PSL use & 1.16 & 0.82 & 1.64 & 0.38 \\
Stage & 0.99 & 0.98 & 1.01 & 0.57 \\
\hline
\end{tabular}

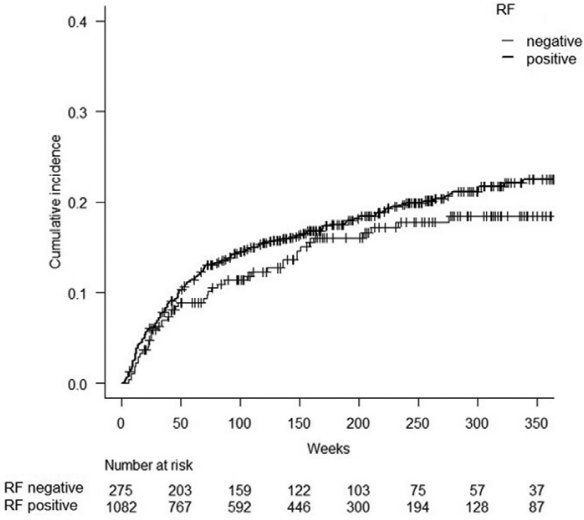

Conclusions: Using the Fine-Grey proportional hazard regression for competing events, this study demonstrated a correlation between the RF positivity and inadequate response to biological therapy on bio-naïve patients with RA.

Disclosure of Interest: None declared

DOI: 10.1136/annrheumdis-2018-eular.4046

\begin{tabular}{|l|l|}
\hline FRI0147 & ANALYSIS OF RADIOGRAPHIC JOINT DESTRUCTION IN \\
THE PATIENTS WITH RHEUMATOID ARTHRITIS WHO \\
HAVE WITHDRAWN, SPACED AND CONTINUED \\
BIOLOGICS AFTER ACHIEVING SUSTAINED REMISSION \\
FROM LOCAL BIOLOGICS REGISTRY
\end{tabular}

Y. Takakubo, J. Nagai, H. Oki, Y. Naganuma, S. Yang, J. Ito, Y. Suzuki, K. Sasaki, M. Takagi. Department of Orthopaedic Surgery, Yamagata University Faculty of Medicine, Yamagata, Japan

Background: Increasing of remission reached by biologics agents in early and established RA patients ${ }^{1,2}$. Data on withdrawn, spacing or reducing of biologics (BIO) medication after sustained remission are limited ${ }^{3,4}$. After withdrawn, spacing or reducing, it is less known to be influenced the radiographic destruction of the joints.

Objectives: To retrospectively analyse the joint destruction using modified Total Sharp Score (mTSS) in RA patients in sustained remission, either withdrawing spacing and continuing $\mathrm{BIO}$.

Methods: Local prefectural (ZAO) registry which is open-labelled $\mathrm{BIO}$ cohort study has registered 356 RA patients. RA Patients were enrolled into this study if they maintained in DAS remission (DAS28-ESR<2.6) more than one year after starting BIO. $\Delta$ mTSS1 was estimated between starting $\mathrm{BIO}$ and withdrawn or spacing or reaching remission in each group, $\Delta$ mTSS2 between the beginning of withdrawn or spacing, or reaching remission in continuing group and latest follow-up or flare-up.

Results: 40 RA patients (32 female) using $\mathrm{BIO}$ was fulfilled in the criteria of this study in ZAO registry. Of 40 RA Patients, 10 has withdrawn $\mathrm{BIO}, 15$ has spaced and 15 has continued it after maintain DAS remission more than one year. Mean age was $43,55,54$ year-old, mean RA affiliation 4.6, 15.3, 9.1 years before BIO and mean duration of remission 6.2, 7.6, 7 years, mean dosage of MTX and PSL was 7.7, 6, $5 \mathrm{mg} /$ week and 1.1, 3, $4 \mathrm{mg} /$ day, respectively. $\Delta \mathrm{mTSS} 1$ and $\Delta \mathrm{mTSS} 2$ was +2.4 and +4.5 in withdrawn group, +3.6 and +0.9 in spacing group, +0.2 and -1.4 in continuing group, respectively (figure $1, p<0.05$ ). Five cases in withdrawing group had resumed $\mathrm{BIO}$ because of flare-up of their disease activity.

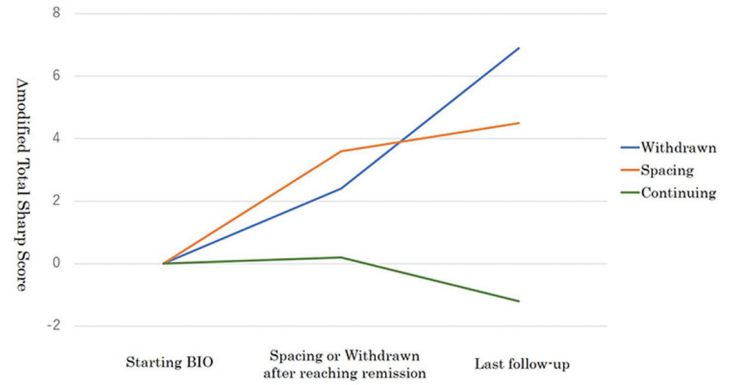

Abstract FRI0147 - Figure 1. Radiographic destruction of joint in each withdrawn, spacing, continuing groups 